\title{
Polyphenolic glycosides isolated from Pogostemon cablin (Blanco) Benth. as novel influenza neuraminidase inhibitors
}

\author{
Fang Liu, Wei Cao, Chao Deng, Zhaoquan Wu, Guangyao Zeng and Yingjun Zhou*
}

\begin{abstract}
Background: Influenza is historically an ancient disease that causes annual epidemics and, at irregular intervals, pandemics. At present, the first-line drugs (oseltamivir and zanamivir) don't seem to be optimistic due to the spontaneously arising and spreading of oseltamivir resistance among influenza virus. Pogostemon cablin (Blanco) Benth. (P. cablin) is an important traditional Chinese medicine herb that has been widely used for treatment on common cold, nausea and fever. In our previous study, we have identified an extract derived from P. cablin as a novel selective neuraminidase (NA) inhibitor.
\end{abstract}

Results: A series of polyphenolic compounds were isolated from P. cablin for their potential ability to inhibit neuraminidase of influenza A virus. Two new octaketides $(\mathbf{1}, \mathbf{2})$, together with other twenty compounds were isolated from P. cablin. These compounds showed better inhibitory activity against NA. The significant potent compounds of this series were compounds $\mathbf{2}\left(\mathrm{IC} \mathrm{C}_{50}=3.87 \pm 0.19 \mu \mathrm{mol} / \mathrm{ml}\right), \mathbf{1 1}, \mathbf{1 2}, \mathbf{1 4}, \mathbf{1 5}, \mathbf{1 9}$ and $\mathbf{2 0}\left(\mathrm{IC} \mathrm{C}_{50}\right.$ was in 2.12 to $3.87 \mathrm{\mu} \mathrm{mol} /$ $\mathrm{ml}$ ), which were about fourfold to doubled less potent than zanamivir and could be used to design novel influenza NA inhibitors, especially compound $\mathbf{2}$, that exhibit increased activity based on these compounds. With the help of molecular docking, we had a preliminary understanding of the mechanism of the two new compounds (1-2) $N A$ inhibitory activity.

Conclusions: Fractions 6 and polyphenolic compounds isolated from fractions 6 showed higher NA inhibition than that of the initial plant exacts. The findings of this study indicate that polyphenolic compounds and fractions 6 derived from P. cablin are potential NA inhibitors. This work is one of the evidence that P. cablin has better inhibitory activity against influenza, which not only enriches the compound library of $P$. cablin, but also facilitates further development and promises its therapeutic potential for the rising challenge of influenza diseases.

Keywords: Octaketide, Polyphenolic glycosides, Pogostemon cablin (Blanco) Benth., Neuraminidase (NA) inhibitory activity

\section{Background}

Influenza can cause serious public health and economic problems, which affects millions of people worldwide. Despite advances in the understanding of molecular and cellular aspects of influenza, the disease remains the major cause of mortality and morbidity among patients with respiratory diseases [1].

*Correspondence: fisher203@126.com

College of Pharmacy, Central South University, Changsha 410013, Hunan, People's Republic of China
Influenza viruses have several proteins that are implicated in virulence: the surface proteins hemagglutinin (HA) and neuraminidase (NA), the polymerase complex (including the PB1, PB2 and PA proteins), and the nonstructural proteins [2]. NA is an antiviral target of high pharmaceutical interest because of its essential role in cleaving sialic acid residues from cell surface glycoprotein and facilitating release of virions from infected cells.

The anti-influenza drugs approved for clinical use are the NA inhibitors (orally administered oseltamivir trade name Tamiflu and inhaled zanamivir trade name 
Relenza). Both of them are sialic acid (Neu5Ac) analogues. Because such inhibitors may be structurally recognized as inhibitors by the cellular NA from the host, this might result in side effects. Therefore, developing novel NA inhibitors to combat influenza virus is desirable.

Natural products, especially those derived from traditional Chinese medicine herbs (TCMH), are still the major source of innovative therapeutic agents for infectious diseases, cancer, lipid disorders and immunomodulation [3]. Pogostemon cablin is an annual herb mostly distributed in the tropical and subtropical regions of Asia. P. cablin has been recorded in Chinese Pharmacopoeia as a traditional herbal medicine for its therapeutic functions, including eliminating heat and dampness, calming nerves, and alleviating fatigue. It is used in traditional Chinese medicine for the treatment of upset stomach, vomiting and diarrhea, headache, and fever [4]. Chemical and pharmacological researches on $P$. cablin have been carried out in recent years [5]. A number of mono- and sesquiterpenoids [6], triterpenoids and steroids [7], flavonoids [8], alkaloids [9] and phenylpropanoid glycosides [10] have been discovered from the title plant.

P. cablin and polyphenolic compounds present in them have gained a lot of interest due to their beneficial health implications. Dietary polyphenolic compounds, especially phenylpropanoid glycosides, exert antioxidant properties and are better inhibitors of NA of influenza A virus [11]. In our ongoing effort to characterize new natural compounds used in Traditional Chinese Medicine (TCM) herbs with interesting chemical structures and/ or pharmaceutical activities, we studied on the chemical constituents of the aerial parts of P. cablin, which led to the isolation of two new octaketides $(\mathbf{1}, \mathbf{2})$, together with other twenty compounds were isolated from $P$. cablin. This is the first report that presents compounds 1-9, 11 and 21-22 in this genus.

In a previous study from our research group, several extracts derived from $P$. Cablin have better inhibitory activity on NA. In extending these studies, we examined the effects of these compounds against NA activity. According to the results obtained, the extracts exhibited better inhibitory activity against NA, and the polyphenolic compounds presents in them are responsible for their biological properties. Our current results imply that these specific plant extracts are a possible source of new natural NA inhibitors (Fig. 1).

\section{Results and discussion}

\section{Structures elucidation of compounds Compound 1:}

Named cytosporone VI, colorless noodle-like crystal with a negative optical rotation $\left([\alpha]_{D}^{15}-9.5, \mathrm{c}=0.5\right.$,
$\mathrm{CHCl}_{3}$ ). The molecular formula of compound $\mathbf{1}$ was determined as $\mathrm{C}_{14} \mathrm{H}_{18} \mathrm{O}_{5}$ from its positive mode HR-ESI MS data at $\mathrm{m} / \mathrm{z} 289.1051[\mathrm{M}+\mathrm{Na}]^{+}$(calcd for $\mathrm{C}_{14} \mathrm{H}_{18} \mathrm{O}_{5} \mathrm{Na}$, 289.1052), which was compatible with ${ }^{1} \mathrm{H}$ NMR and ${ }^{13} \mathrm{C}$ NMR data. The ${ }^{1} \mathrm{H}$ NMR and ${ }^{13} \mathrm{C}$ NMR spectral data (Table 1) of compound 1, in combination with HSQC, indicated the co-existence in the molecule of two metacoupled aromatic methines: $\delta_{\mathrm{H}} 6.29(1 \mathrm{H}, \mathrm{d}, J=4 \mathrm{~Hz}), \delta_{\mathrm{C}}$ 101.42 and $\delta_{\mathrm{H}} 6.25(1 \mathrm{H}, \mathrm{d}, J=4 \mathrm{~Hz}), \delta_{\mathrm{C}} 110.43$; one carboxyl group: $\delta_{\mathrm{C}} 172.75$; and a methylene: $\delta_{\mathrm{H}} 3.50(2 \mathrm{H}), \delta_{\mathrm{C}}$ 38.94 , which is presumably located between the phenyl and carboxyl groups. Furthermore, a side chain was indicated by one ketone group: $\delta_{\mathrm{C}} 211.28$; two methyl groups: $\delta_{\mathrm{H}} 0.90(3 \mathrm{H}, \mathrm{t}), \delta_{\mathrm{C}} 10.91$ and $\delta_{\mathrm{H}} 1.08(3 \mathrm{H}, \mathrm{d}, J=8.5 \mathrm{~Hz})$, $\delta_{\mathrm{C}} 14.87$, a methylene: $\delta_{\mathrm{H}} 1.35(1 \mathrm{H}, \mathrm{m}), 1.75(1 \mathrm{H}, \mathrm{m}), \delta_{\mathrm{C}}$ 25.94, and a methine: $\delta_{\mathrm{H}} 3.40(1 \mathrm{H}, \mathrm{m}), \delta_{\mathrm{C}} 47.23$. The side chain was determined to be 2- methylbutan-1-one by the ${ }^{1} \mathrm{H}-{ }^{1} \mathrm{H}$ COSY and TOCSY spectra, revealing the ${ }^{1} \mathrm{H}-{ }^{1} \mathrm{H}$ spin systems of $\mathrm{H}-10 / \mathrm{H}-11 / \mathrm{H}-12$ and $\mathrm{H}-10 / \mathrm{H}-13$, and the HMBC spectra correlations of $\mathrm{H}-12 / \mathrm{C}-10, \mathrm{H}-12 / \mathrm{C}-11$, $\mathrm{H}-13 / \mathrm{C}-9$ and $\mathrm{H}-13 / \mathrm{C}-11$ (Fig. 2). In conjunction with other key HMBC correlations of $\mathrm{H}-2 / \mathrm{C}-1, \mathrm{H}-2 / \mathrm{C}-8, \mathrm{H}-4$ / $\mathrm{C}-2$, H-6/C-4, H-6/C-8, and H-10/C-8, these observations suggested that compound 1 was assigned as a 5, 7-dihydroxy-8-(2-methylbutan-1-onyl)-ethyl phenylmethyl ester. This is structurally associated with cytosporone analogues. The absolute configuration of $\mathrm{C}-10$ in the side chain was established as $\mathrm{R}$ by comparing the specific rotation value $\left([\alpha]_{D}^{15}-9.5, \mathrm{c}=0.5, \mathrm{CHCl}_{3}\right)$ for 1 to those known synthetic isomeric compounds, which showed a negative specific rotation for the R-configuration and a positive specific rotation for the S-configuration in the side chain of the related synthetic ones ((2R)-1-phenyl-2-methylbutan-lone, $[\alpha]_{D}^{15}-36.9$ and (2S)-1-phenyl-2-methylbutan-l-one, $\left.[\alpha]_{D}^{15}+36.8\right)$ [12]. On the basis of above data, the structure of 1 was elucidated as 5, 7-dihydroxy-8-((2R)-2-methylbutan-1-onyl)-methyl phenylacetate.

\section{Compound 2:}

White amorphous powder $(\mathrm{MeOH})$, the molecular formula of compound 2 was determined to be $\mathrm{C}_{19} \mathrm{H}_{26} \mathrm{O}_{10}$ on the basis of HR-ESI MS (m/z $437.1390[\mathrm{M}+\mathrm{Na}]^{+}$, calcd for $\left.\mathrm{C}_{19} \mathrm{H}_{26} \mathrm{O}_{10} \mathrm{Na}, 437.1424\right)$ in the positive mode HR-ESI MS. For the ${ }^{1} \mathrm{H}$ NMR and ${ }^{13} \mathrm{C}$ NMR spectral data of compound 2 see Table 1 . The aglucone of compound 2 was an analogue compound of $\mathbf{1}$, and the HMBC spectra correlation between $\mathrm{H}-1^{\prime}$ and $\mathrm{C}-7$ confirmed the position of glucopyranosyl moiety. The absolute configuration of C-10 in the side chain was established as $\mathrm{R}$ for the $\mathrm{CD}$ spectra of $2(217 \mathrm{~nm}, \Delta \varepsilon-9.49 ; 208 \mathrm{~nm}, \Delta \varepsilon+5.01)$ which in accordance with compound $\mathbf{1}(218 \mathrm{~nm}, \Delta \varepsilon-15.47 ; 205 \mathrm{~nm}, \Delta \varepsilon$ +9.12) (Fig. 3). On the basis of above data, the structure of 2 was elucidated as 5, 7-dihydroxy-8-((2R)-2-methylbutan-1-onyl)-phenylacetic acid 7-O- $\beta$-D-glucopyranoside. 


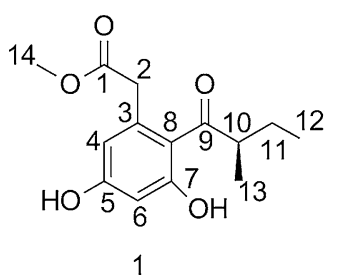<smiles>CC1=CC(=O)CC(C)(C)[C@]1(O)/C=C/C(C)(C)O[C@@H]1OC(CO)[C@@H](O)[C@H](O)[C@H]1O</smiles>

4<smiles>CC1(C)C2=CC(=O)CC1C[C@H]1[C@H](OC2)O[C@H](CO)[C@@H](O)[C@@H]1O</smiles>

7<smiles>OC[C@H]1O[C@@H](OCCc2ccc(O)cc2)[C@H](O)[C@@H](O)[C@@H]1O</smiles>

13<smiles>[R]c1cc(-c2cc(=O)c3c(O)c([R])c([R20])cc3o2)ccc1O</smiles>
$18 \mathrm{R} 1=\mathrm{OCH} 3, \mathrm{R} 2=\mathrm{Glu}, \mathrm{R} 3=\mathrm{OH}$<smiles>Nc1nc2c(ncn2C2OC(CO)C(O)C2O)c(=O)[nH]1</smiles>

21<smiles>CCC(C)C(=O)c1c(CC(=O)O)cc(O)cc1O[C@@H]1O[C@H](CO)[C@@H](O)[C@H](O)[C@H]1O</smiles>

2<smiles>CC1=C(/C=C/[C@@H](C)O[C@@H]2O[C@H](CO)[C@@H](O)[C@H](O)[C@H]2O)C(C)(C)CCC1=O</smiles>

5<smiles>[R9]C[C@H]1O[C@H](OC[C@H](O)c2ccc(O)c(O)c2)[C@H](O)[C@@H]([R20])[C@H]1[R20]</smiles>

$8 \mathrm{R} 1=\mathrm{H}, \mathrm{R} 2=$ Caffeoyl, R3=H 9 R1=Rha, R2=H, R3=Caffeoyl $10 \mathrm{R} 1=$ Rha, R2=Caffeoyl, R3=H<smiles>[R6]OC[C@H]1O[C@@H]2OC[C@@H](c3ccc(O)c(O)c3)O[C@H]2C([R20])[C@H]1[R20]</smiles>
14 R1=Rha, R2=Caffeoyl, R3=H 15 R1=Rha, R2=H, R3=Caffeoyl<smiles>O=C(/C=C/c1ccc(O)c(O)c1)OC(Cc1ccc(O)c(O)c1)C(=O)O</smiles>

16<smiles>COc1cc([C@H]2c3cc(O)c(OC)cc3[C@H](C=O)[C@H]2CO)ccc1O</smiles>

22
19 R1=Rha, R2=H, R3=Caffeoyl 20 R1=Rha, R2=Caffeoyl, R3=H<smiles>[R]O[C@H]1[C@@H](O)[C@@H](O)O[C@H](COC(=O)/C=C/c2ccc(O)c(O)c2)[C@@H]1O</smiles>

$11 \mathrm{R}=\mathrm{H}$ $12 \mathrm{R}=\mathrm{Rha}$<smiles>CC1=C(/C=C/C(C)=C/[OH+][C@@H]2O[C@H](CO)[C@@H](O)[C@H](O)[C@H]2O)C(C)(C)CCC1=O</smiles><smiles>[R9]C[C@H]1O[C@H](OCCc2ccc(O)c(O)c2)[C@H](O)[C@@H]([R20])[C@H]1O[R20]</smiles> 
Table $1{ }^{1} \mathrm{H}(500 \mathrm{MHz})$ and ${ }^{13} \mathrm{C}(125 \mathrm{MHz})$ NMR spectral data of compounds 1 and 2

\begin{tabular}{|c|c|c|c|c|}
\hline \multirow[t]{2}{*}{ Position } & \multicolumn{2}{|l|}{$1^{a}$} & \multicolumn{2}{|l|}{$2^{b}$} \\
\hline & $\delta_{c}$ & $\delta_{H}$ & $\delta_{\mathrm{c}}$ & $\delta_{H}$ \\
\hline 1 & 172.75 & & 172.08 & \\
\hline 2 & 38.94 & 3.50 & 38.77 & 3.33 \\
\hline 3 & 135.79 & & 135.80 & \\
\hline 4 & 119.83 & & 122.53 & \\
\hline 5 & 158.30 & & 156.88 & \\
\hline 6 & 101.42 & $6.29, \mathrm{~d}(4)$ & 100.86 & 6.49, br s \\
\hline 7 & 159.95 & & 159.59 & \\
\hline 8 & 110.43 & $6.25, \mathrm{~d}(4)$ & 112.28 & $6.37, \mathrm{br} \mathrm{s}$ \\
\hline 9 & 211.28 & & 209.76 & \\
\hline 10 & 47.23 & $3.40, \mathrm{~m}$ & 47.44 & 3.25 \\
\hline 11 & 25.94 & $\begin{array}{l}1.35, \mathrm{~m} \\
1.75, \mathrm{~m}\end{array}$ & 25.75 & $\begin{array}{l}1.24, \mathrm{~m} \\
1.65, \mathrm{~m}\end{array}$ \\
\hline 12 & 10.91 & $0.90, \mathrm{t}$ & 11.90 & $0.82, \mathrm{t}$ \\
\hline 13 & 14.87 & $1.08, d(8.5)$ & 15.76 & $0.98, d(6.5)$ \\
\hline 14-OCH3 & 51.02 & $3.68, \mathrm{~s}$ & & \\
\hline Glu-1 & & & 100.25 & $4.93, d(7.5)$ \\
\hline Glu-2 & & & 77.54 & 3.31 \\
\hline Glu-3 & & & 77.45 & 3.31 \\
\hline Glu-4 & & & 69.94 & 3.16 \\
\hline Glu-5 & & & 73.82 & 3.19 \\
\hline Glu-6 & & & 61.00 & $\begin{array}{l}3.70 \\
3.49\end{array}$ \\
\hline
\end{tabular}

a Measured in $\mathrm{CD}_{3} \mathrm{OD}$

${ }^{\mathrm{b}}$ Measured in DMSO- $d_{6}, \delta$ Chemical shifts are given in ppm, $J$ values are in parentheses and reported in $\mathrm{Hz}$
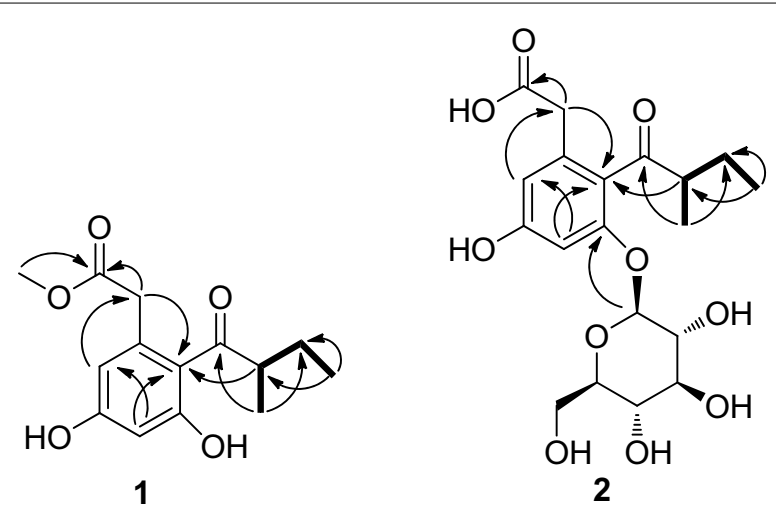

Fig. 2 Key HMBCs $(\rightarrow)$ and ${ }^{1} \mathrm{H}^{-1} \mathrm{H}$ COSY (bold) correlations of compound 1-2

The structures of compound (7 E, 9 S)-9-Hydroxy-5, 7-megastigmadien-4-one 9-O- $\beta$-D-glucopyranoside (5) and (7 E, 9 R)-9-Hydroxy-5, 7-megastigmadien-4-one 9-O- $\beta$-D-glucopyranoside (6) [13], which were isolated from $P$. cablin for the first time, were deduced by analyzing the MS, 1D, 2D NMR spectra, rotation and CD curves (Fig. 4). The CD curves of compounds $\mathbf{5}$ and $\mathbf{6}$ were also firstly reported in this report.

The compounds 3,4 and 7-22 were identified by comparison of their physicochemical data (NMR, MS, $[\alpha]$ ) with those reported in the literature as (6 S, $7 \mathrm{E}, 9 \mathrm{~S})-6$, 9-Dihydroxy-4, 7-megastigmadien-3-one 9- O- $\beta$-Dglucopyranoside (3) [14], (6 S, 7 Z, 9 R)-6, 9-Dihydroxy-4, 7-megastigmadien -3-one 9- O- $\beta$-D-glucopyranoside (4) [15], and Vervenone- 10-O- $\beta$-D-glucopyranoside (7) [16], 2- (3, 4-dihydroxyphenyl)-2-hydroxyethyl, 4- [(2E)-3- (3, 4-dihydroxyphenyl)-2-propenoate] $\beta$ - D- Glucopyranoside (8) [17], isocampneoside II (9), campneoside II (10), 4- [(2E)-3- (3, 4-dihydroxyphenyl)-2-propenoate $\beta$ D- Glucopyranoside (11), cistanoside F (12), descaffeoyl crenatoside (13) [18, 19], crenatoside (14), isocrenatoside (15) [20], rosmarinic acid (16), apigenin (17) [21], nepetin (18), [22] isopedicularioside G (19), pedicularioside G (20) [23], guanosine (21) [24], 6-Hydroxy-4-(4-hydroxy3-methoxyphenyl)-3-hydroxymethyl-7-methoxy-3, 4-dihydro-2-naphthaldehyde (22) [25], respectively (Additional file 1). The compounds 1-9, 11, 18, 19 and 21-22 were isolated from $P$. cablin for the first time.

\section{Evaluation of NA inhibition activity}

NA remains an attractive anti-influenza drug target, while the emergence of viruses resistant to currently available drugs has presented a new challenge. Therefore, compounds 1-22 and fractions 1-7 (Fig. 5) were tested for their inhibitory effects against the influenza virus NA in vitro with the commercial NA inhibitory screening kit. Even though a number of biological activity studies on this plant have been performed, so far only a few anti-influenza virus constituents from $P$. cablin have been reported. In this study, the half inhibitory concentration $\left(\mathrm{IC}_{50}\right)$ of compounds 1-22 were evaluated for their inhibitory effects against the influenza virus NA in vitro as a screening system. The NA inhibitory activity experiment results are shown in Tables 2 and 3 (Additional file 2).

Good oral availability can be achieved by right balance between partitioning and solubility properties. To understand the properties of the proposed compounds better, we utilized Molinspiration [26] to predict some properties of the typical compounds (1, 2, 16, 20 and 22) (Table 4), and applied the Lipinski's rule of five [27] to see whether all passed the criteria. Lipinski's rule of five acts as a filter for drug like properties and states that a potential molecule is orally active if it's molecular weight is $\leqslant 500 \mathrm{da}, \log \mathrm{P} \leqslant 5$, number of hydrogen bond acceptors $\leqslant 10$, number of hydrogen bond donors $\leqslant 5$. Under the Lipinski's rule of five, compounds $(1,2,16,20$ and 22) presenting mi $\log \mathrm{P}(<5)$ suggested that they may all have good oral bioavailability, and compounds $\mathbf{1}$ and $\mathbf{2 2}$ 

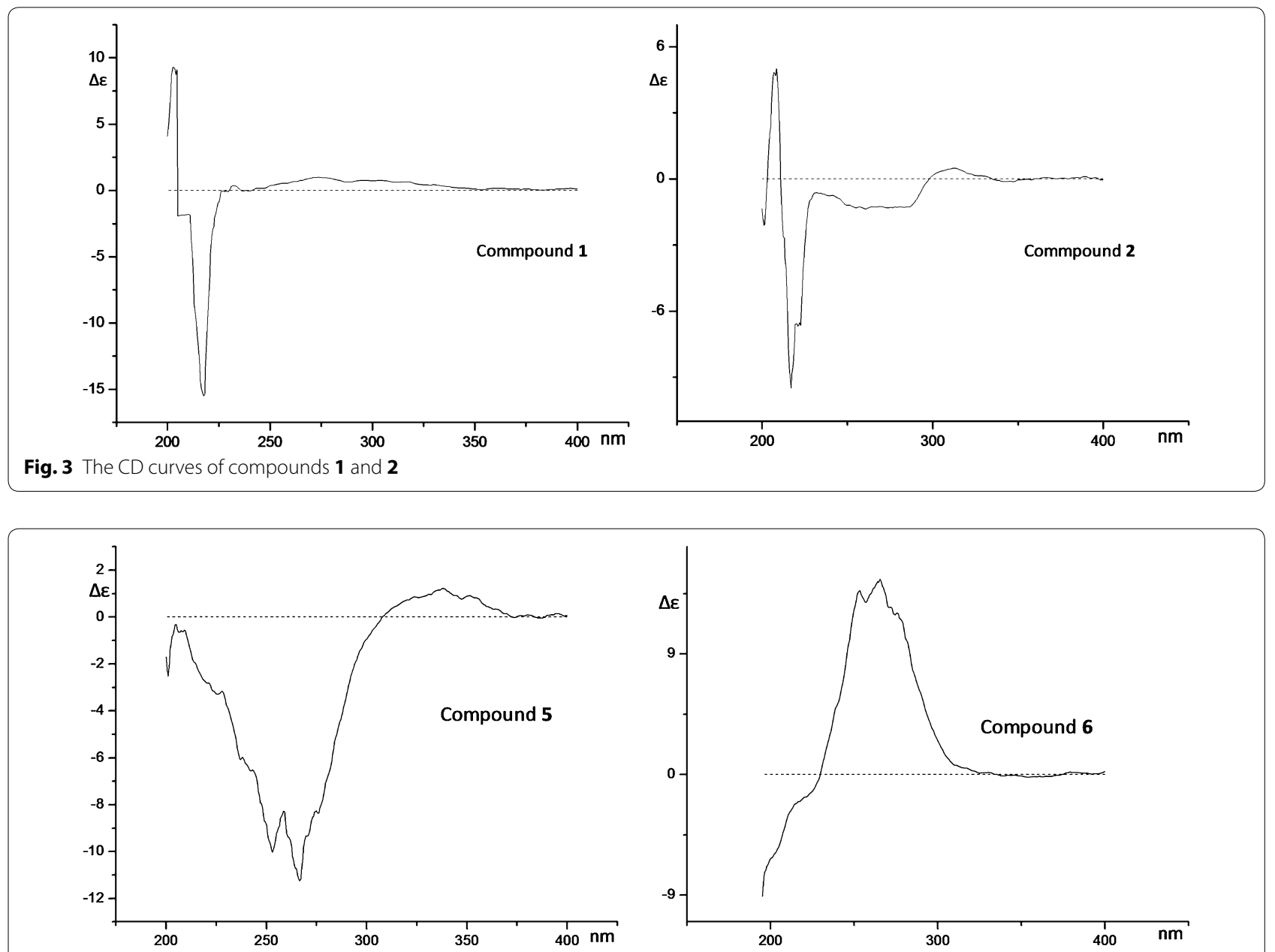

Fig. 4 The CD curves of compounds 5 and $\mathbf{6}$

might be two lead compounds for anti-influenza. (mi log P: logarithm of compound partition coefficient between n-octanol and water).

\section{Molecular docking studies}

Earlier crystallographic and ensuing SAR studies have revealed that the active site of NA could be divided into four major binding sites [28]. All NA inhibitors on the market or in clinical phases possess strong structural resemblance in those parts, which correspond to the fact that the four pockets are critical for interaction with the active site of NA.

The pocket $\mathrm{C} 1$ is comprised of positively charged guanidino groups of arginines 118, 292 and 371 and interacts with the carboxylate. In pocket C5, Arg 152 functions as the hydrogen-bond donor. Trp 178 and Ile 222 comprise a small hydrophobic region. In pocket $\mathrm{C} 4$, usually a guanidine or an amine group participates in charge-charge interactions and hydrogen bonds to Glu 119. Asp 151, and/or Glu 227. In pocket C6, Glu 276, the side chain of Arg 152, the amidic carbonyl of Trp 178 and Asp 151 form a new hydrophobic binding pocket. Moreover, Glu 277 and Tyr 406 are believed to play a critical role in the catalytic activity of NA [29, 30].

From the activity assay results, compounds $\mathbf{1}$ and $\mathbf{2}$ showed better inhibitory activities against NA. To provide a further insight on the observed activities, the binding of compounds $\mathbf{1}$ and $\mathbf{2}$ in the active site of NA is shown in Fig. 6. we find that the- $\mathrm{COOH}$ group of compound 2 interacts with the pocket $\mathrm{C} 4$ of NA active site by hydrogen bond with Glu 119 of this subsite, anomeric carbon of glucose binds to the pocket $\mathrm{C} 4$ by hydrogen bond interaction with Asp 151, and 5-OH group forms hydrogen bond with Glu 227 of pocket $\mathrm{C} 4$.

Moreover, for compound $\mathbf{1}$, the 7-OH group binds to the pocket $\mathrm{C} 6$ by hydrogen bond interaction with Glu 277, the 1-CO-group forms a hydrogen bond with Arg 152 and Arg 292 of pocket $\mathrm{C} 1$, and the $5-\mathrm{OH}$ group binds to the pocket $\mathrm{C} 4$ by hydrogen bond interaction with Asp151 (Fig. 7). 


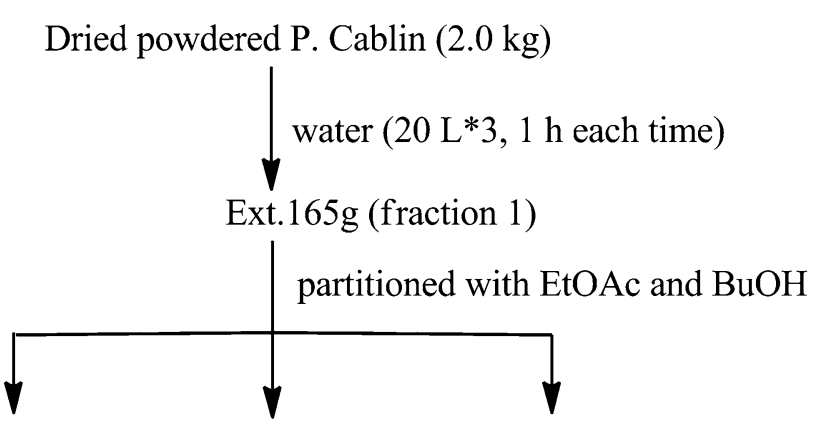

EtOAc-soluble extract $\mathrm{BuOH}$-soluble extract $\mathrm{H}_{2} \mathrm{O}$-soluble extract $32 \mathrm{~g}$ (fraction 2) $\quad 56 \mathrm{~g}$ (fraction 3) $\quad 71 \mathrm{~g}$ (fraction 4)

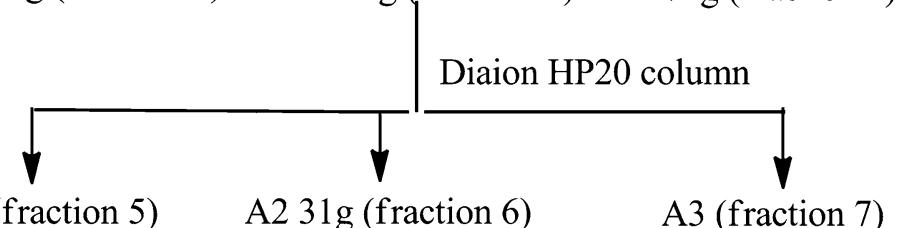
A1 (fraction 5)
A2 31g (fraction 6)
A3 (fraction 7)

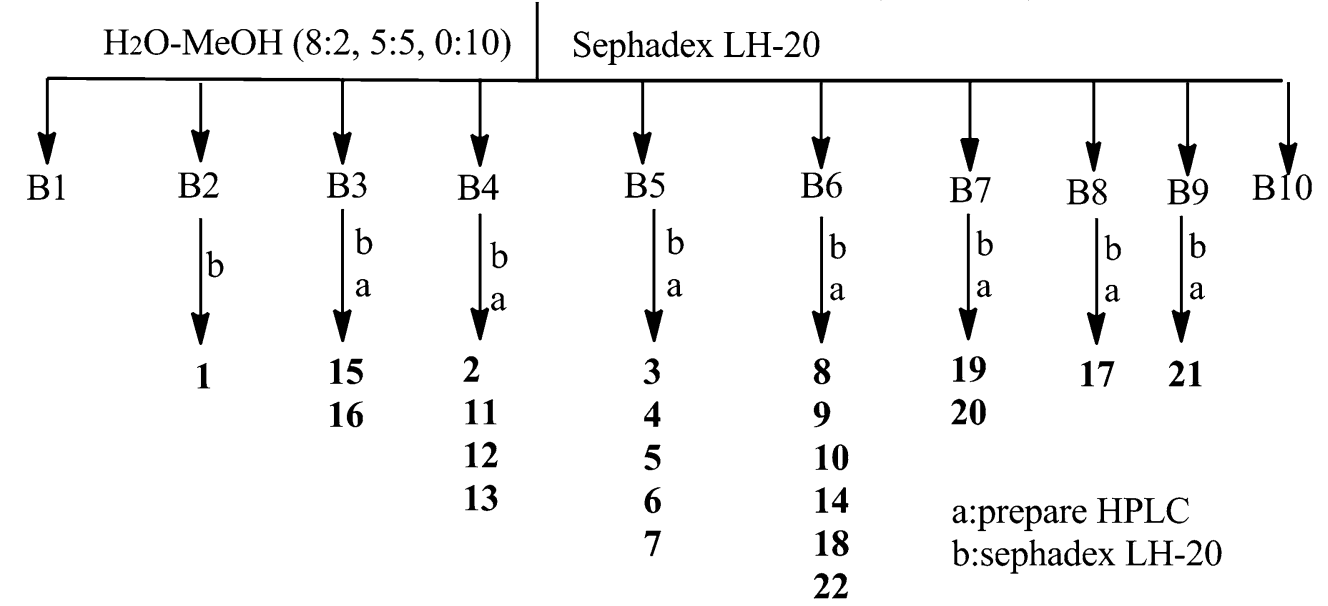

Fig. 5 Process for the separation of compounds 1-22

Table 2 NA inhibition activity of compounds 1-22

\begin{tabular}{|c|c|c|c|c|c|}
\hline Compound & $I C_{50}(\mu \mathrm{mol} / \mathrm{ml})$ & Compound & $I C_{50}(\mu \mathrm{mol} / \mathrm{ml})$ & Compound & $I C_{50}(\mu \mathrm{mol} / \mathrm{ml})$ \\
\hline 1 & $8.40 \pm 1.20$ & 9 & $6.08 \pm 0.20$ & 17 & $4.69 \pm 0.29$ \\
\hline 2 & $3.87 \pm 0.19$ & 10 & $6.53 \pm 0.38$ & 18 & $3.29 \pm 0.04$ \\
\hline 3 & $11.62 \pm 0.48$ & 11 & $3.60 \pm 0.02$ & 19 & $2.74 \pm 0.03$ \\
\hline 4 & $10.99 \pm 1.15$ & 12 & $2.99 \pm 0.12$ & 20 & $2.12 \pm 0.04$ \\
\hline 5 & $10.93 \pm 0.48$ & 13 & $7.87 \pm 0.13$ & 21 & $32.67 \pm 4.73$ \\
\hline 6 & $19.94 \pm 1.95$ & 14 & $3.30 \pm 0.12$ & 22 & $4.70 \pm 0.05$ \\
\hline 7 & $>200$ & 15 & $3.64 \pm 0.17$ & & \\
\hline 8 & $6.32 \pm 0.38$ & 16 & $2.27 \pm 0.09$ & Zanamivir & $0.93 \pm 0.02$ \\
\hline
\end{tabular}

Zanamivir was the positive control; each value represents the mean $\pm \operatorname{SD}(n=3)$

The binding of compound $\mathbf{1}$ in the active site of NA showed that the three pockets $(\mathrm{C} 1, \mathrm{C} 4, \mathrm{C} 6)$ of the active site of NA were occupied, although not so well as zanamivir, but still can be a lead compound.

\section{Methods}

\section{General information}

Optical rotations were recorded on a Jasco P-2000 automatic digital polarimeter. The ${ }^{1} \mathrm{H} N M R,{ }^{13} \mathrm{C} N M R,{ }^{1} \mathrm{H}-{ }^{1} \mathrm{H}$ 
Table 3 NA inhibition activity of fraction 1-7

\begin{tabular}{ll}
\hline Fractions & Inhibition rate $\% \mathbf{~} \mathbf{~} \mathbf{~ g} / \mathbf{m l}, \mathbf{D M S O})$ \\
\hline 1 & $44.71 \pm 1.53$ \\
2 & $35.71 \pm 1.15$ \\
3 & $69.70 \pm 1.16$ \\
4 & $20.05 \pm 1.00$ \\
5 & $26.38 \pm 0.58$ \\
6 & $90.69 \pm 1.53$ \\
7 & $18.72 \pm 0.58$ \\
\hline
\end{tabular}

Each value represents the mean $\pm S D(n=3)$

COSY, HSQC and HMBC spectra were recorded on a Bruker AM 500 spectrometer with TMS as the internal standard at $500 \mathrm{MHz}$ and $125 \mathrm{MHz}$ for ${ }^{1} \mathrm{H}$ and ${ }^{13} \mathrm{C}$. The enzyme activity inhibition assay was carried out on a microplate spectrophotometer (Gemini EM; Molecular Devices). Circular dichroism (CD) spectra were recorded on a CD spectrometer (JASCO, J-815-150S, Japan).
Optical rotations were recorded on an automatic digital polarimeter (Shenguang SGW-3, China). Preparative HPLC: Agilent 1100 Series HPLC system, a reverse-phase C18 column (YMC-Pack ODS-A, 250*20 mm, $5 \mu \mathrm{m}$, YMC Co., Ltd, Kyoto, Japan). Column chromatography was performed with Diaion HP20 (Mitsubishi, Japan) and Sephadex LH-20 (Pharmacia (GE)). TLC was carried out on precoated silica gel GF 254 plates (Qingdao Haiyang Chemical Co. Ltd), and spots were visualized under UV light ( 254 or $365 \mathrm{~nm}$ ) or detected by spraying with $10 \%$ $\mathrm{H}_{2} \mathrm{SO}_{4}$ in $\mathrm{EtOH}$ followed by heating.

\section{Plant material}

The aerial part of $P$. cablin was purchased from Suixi county, Guangdong province, China, in September 2014. The botanical identification was made by Associate Prof. Jin-ping Li. A voucher specimen (NO.GHX140918) was deposited in College of Pharmacy, Central South University.

Table 4 Theoretical prediction of properties of compounds 1, 2, 16, 20 and 22

\begin{tabular}{|c|c|c|c|c|c|c|c|c|}
\hline Compound & mi $\log P$ & TPSA & MW & nON & nOHNH & nviolations & Volume & nrotb \\
\hline 1 & 2.49 & 83.83 & 266.29 & 5 & 2 & 0 & 247.15 & 6 \\
\hline 2 & -0.38 & 173.98 & 414.41 & 10 & 6 & 1 & 361.74 & 8 \\
\hline 16 & 1.63 & 144.52 & 360.32 & 8 & 5 & 0 & 303.54 & 7 \\
\hline 20 & -0.45 & 245.29 & 624.59 & 15 & 9 & 3 & 532.50 & 11 \\
\hline 22 & 2.01 & 96.22 & 356.37 & 6 & 3 & 0 & 316.61 & 5 \\
\hline
\end{tabular}

mi log P logarithm of compound partition coefficient between n-octanol and water; TPSA topological polar surface area; $M W$ molecular weight; $n O N$ number of hydrogen bond acceptors; $n O H N H$ number of hydrogen bond donors; Nrotb number of rotatable bonds

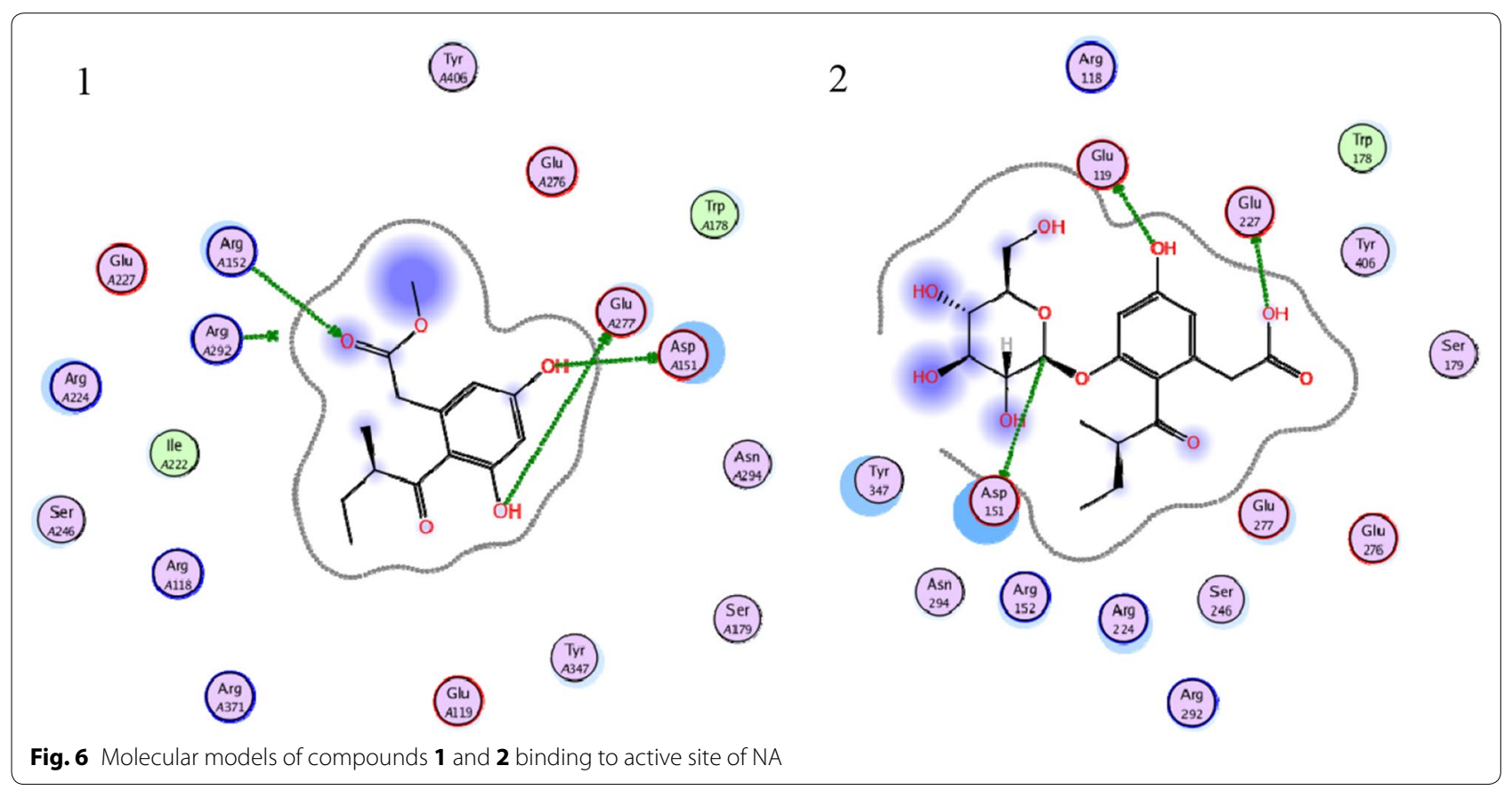



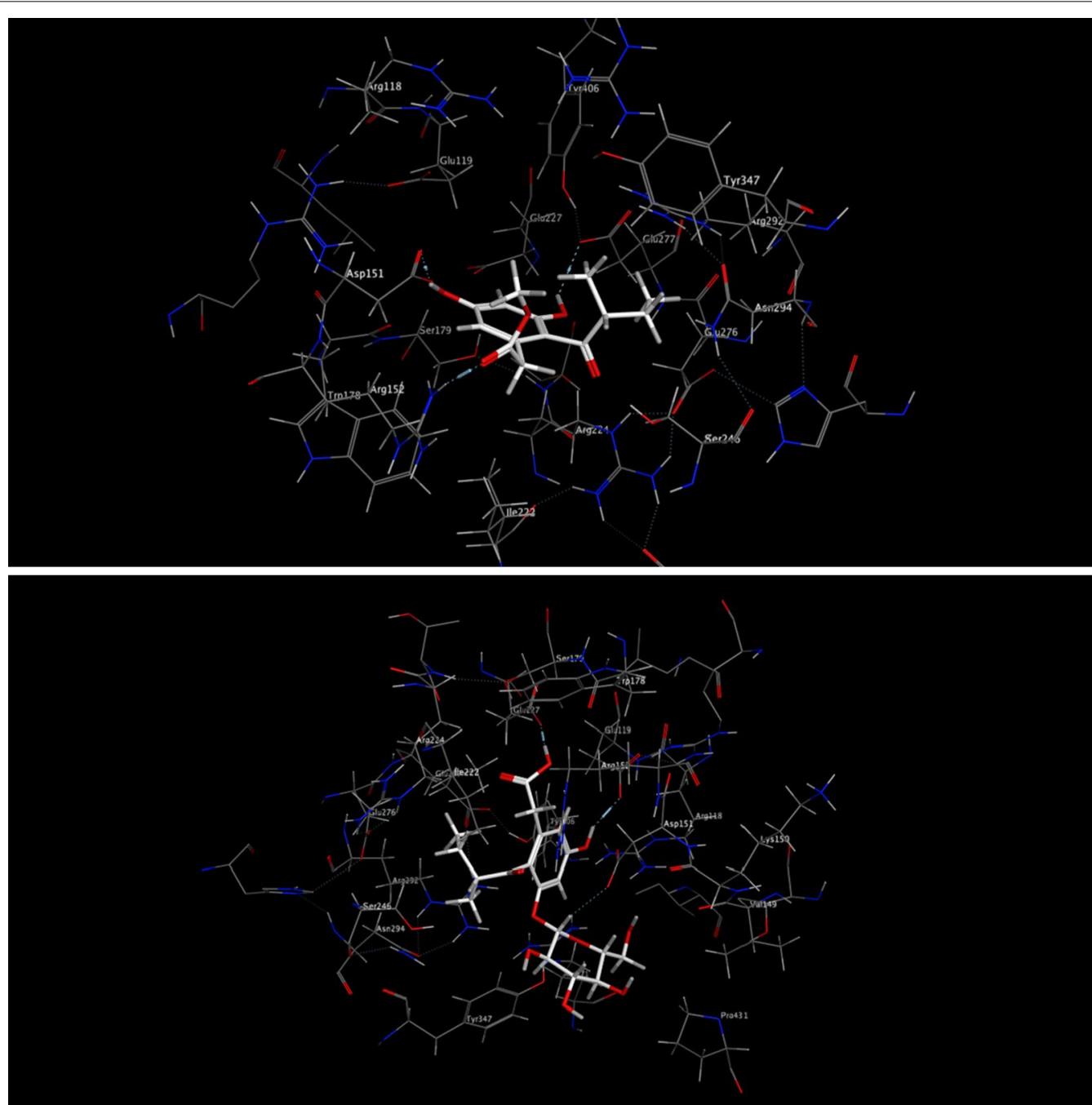

Fig. 7 Detailed view of the docking results of compounds $\mathbf{1}$ and $\mathbf{2}$ in the active site of neuraminidase (PDB ID: 2HU4). The Sky blue lines and numbers show the potential hydrogen bonds and bond length. The first one is compound $\mathbf{1}$, and the second one is compound $\mathbf{2}$

\section{Extraction and isolation}

Dried powdered $P$. Cablin $(2.0 \mathrm{~kg})$ was extracted with water $(20 \mathrm{~L} \times 3,1 \mathrm{~h}$ each time) by reflux. The extracts were then concentrated under vacuum to afford a crude extract (165 g), which was suspended in $\mathrm{H}_{2} \mathrm{O}$ and successively partitioned with EtOAc and $\mathrm{BuOH}$, yielding $32 \mathrm{~g}$ of EtOAc-soluble extract, $56 \mathrm{~g}$ of $\mathrm{BuOH}$-soluble extract and $71 \mathrm{~g}$ of $\mathrm{H}_{2} \mathrm{O}$-soluble extract. $\mathrm{BuOH}-\mathrm{Solu}$ ble extract $(56 \mathrm{~g})$ was applied to a Diaion HP20 column $(10 \times 200 \mathrm{~cm})$ with a step gradient elution of EtOH- $\mathrm{H}_{2} \mathrm{O}$ (v/v 0:1, 4:6, 9.5:0.5) to provide three factions: A1, A2 and A3. A2 (31 g) was chromatographed over a Sephadex LH-20 column $(6 \times 250 \mathrm{~cm})$ eluted with $\mathrm{H}_{2} \mathrm{O}-\mathrm{MeOH}$ system $(8: 2,5: 5,0: 10)$ to give B1-B10.

B2 (300 mg) was chromatographed on a Sephadex LH-20 column $(2 \times 150 \mathrm{~cm})$ eluted with $\mathrm{MeOH}$ to yield B2-1, then B2-1 on a Sephadex LH-20 column $(2 \times 90 \mathrm{~cm}) \mathrm{CH}_{2} \mathrm{Cl}_{2}-\mathrm{MeOH}$ system (8:2) to give compound 1 (11 mg, TLC: $\left.\mathrm{CH}_{2} \mathrm{Cl}_{2}-\mathrm{MeOH} 10-0.1, \mathrm{Rf}=0.3\right)$.

B3 was chromatographed on a Sephadex LH-20 column $(2 \times 150 \mathrm{~cm})$ eluted with $\mathrm{MeOH}$ system and then was purified by preparative reverse-phase HPLC eluted with $40 \% \mathrm{MeOH} / \mathrm{H}_{2} \mathrm{O}(+0.2 \%$ formic acid (FA)) to give compound $15\left(7 \mathrm{mg}, \mathrm{t}_{\mathrm{R}}=23 \mathrm{~min}\right)$ and compound 16 $\left(8 \mathrm{mg}, \mathrm{t}_{\mathrm{R}}=19 \mathrm{~min}\right)$.

B4 was chromatographed on a Sephadex LH-20 column $(2 \times 150 \mathrm{~cm})$ eluted with $\mathrm{MeOH}$ system, and then five fractions (D1-D5) were got. D2 was on a Sephadex LH-20 column $(2 \times 150 \mathrm{~cm})$ eluted with $\mathrm{MeOH}$ system to give two fractions D2-1 and D2-2, then D2-1 and D2-2 were chromatographed on a Sephadex LH-20 column $(2 \times 90 \mathrm{~cm})$ eluted with $\mathrm{CH}_{2} \mathrm{Cl}_{2}-\mathrm{MeOH}$ system (8:2) to give compound 
$11(8 \mathrm{mg})$ and compound 12 (9 mg). D3 eluted with $\mathrm{MeOH}$ was purified by a Sephadex LH-20 column $(2 \times 150 \mathrm{~cm})$, and then to give three fractions: D3-1, D3-2 and D3-3. D3-1 was purified by a Sephadex LH-20 column $(2 \times 90 \mathrm{~cm})$ eluted with $\mathrm{CH}_{2} \mathrm{Cl}_{2}-\mathrm{MeOH}$ system (1:1) and then was purified by preparative reverse-phase HPLC eluted with $15 \%$ $\mathrm{MeCN} / \mathrm{H}_{2} \mathrm{O}(+0.2 \% \mathrm{FA})$ to give compound $13(7 \mathrm{mg}$, $t_{R}=16.5$ min). D3-3 was purified by a Sephadex LH-20 column $(2 \times 90 \mathrm{~cm})$ eluted with $\mathrm{MeOH}$ and then eluted with $\mathrm{CH}_{2} \mathrm{Cl}_{2}-\mathrm{MeOH}$ system (1:1) and purified by a Sephadex LH-20 column $(2 \times 150 \mathrm{~cm})$ to give compound $2(21 \mathrm{mg}$, TLC: EtOAc-FA- $\left.\mathrm{H}_{2} \mathrm{O}: 10-1-1, \mathrm{Rf}=0.4\right)$.

B5 (1.1 g) was chromatographed on a Sephadex LH-20 column $(2 \times 150 \mathrm{~cm})$ eluted with $\mathrm{CH}_{2} \mathrm{Cl}_{2} \mathrm{MeOH}$ system (5:5) to give $\mathrm{C} 1-\mathrm{C} 8, \mathrm{C} 3(107 \mathrm{mg})$ chromatographed on a Sephadex LH-20 column $(2 \times 90 \mathrm{~cm})$ eluted with $\mathrm{H}_{2} \mathrm{O}$. $\mathrm{MeOH}$ system (5:5) to yield three fractions: C3-1 (36 mg), C3-2 (26 mg), C3-3 (50 mg). C3-1 was subsequently purified by preparative reverse-phase HPLC eluted with $11 \% \mathrm{MeCN} / \mathrm{H}_{2} \mathrm{O}(+0.2 \% \mathrm{FA})$ to give compounds $3\left(9 \mathrm{mg}, \mathrm{t}_{\mathrm{R}}=18.5 \mathrm{~min}\right), 4$ (13 mg, $\left.\mathrm{t}_{\mathrm{R}}=20.5 \mathrm{~min}\right), \mathrm{C} 3-3$ was subsequently purified by preparative reverse-phase HPLC eluted with $14 \% \mathrm{MeCN} / \mathrm{H}_{2} \mathrm{O}(+0.2 \% \mathrm{FA})$ to give $7\left(12 \mathrm{mg}, \mathrm{t}_{\mathrm{R}}=27.5 \mathrm{~min}\right)$. C4 (98 $\mathrm{mg}$ ) was subsequently purified by a Sephadex LH-20 column $(2 \times 90 \mathrm{~cm})$ eluted with $\mathrm{H}_{2} \mathrm{O}-\mathrm{MeOH}$ system (5:5) to yield one fraction: $\mathrm{C} 4-1$ (33 mg). C4-1 was subsequently purified by preparative reverse-phase HPLC eluted with $12 \% \mathrm{MeCN} / \mathrm{H}_{2} \mathrm{O}$ $(+0.2 \% \mathrm{FA})$ to give compound $5\left(8 \mathrm{mg}, \mathrm{t}_{\mathrm{R}}=25.5 \mathrm{~min}\right)$ and $6\left(16 \mathrm{mg}, \mathrm{t}_{\mathrm{R}}=26.5 \mathrm{~min}\right)$.

B6 eluted with $\mathrm{MeOH}$ was purified by a Sephadex LH-20 column $(4 \times 150 \mathrm{~cm})$, to yield five fractions: E1-E5. E2 was purified by preparative reverse-phase HPLC eluted with $17 \% \mathrm{MeCN} / \mathrm{H}_{2} \mathrm{O}(+0.2 \% \mathrm{FA})$ to give compound $11\left(t_{R}=16.5 \mathrm{~min}\right)$ and compound 10 $\left(t_{R}=23.5 \mathrm{~min}\right)$, then compounds 10 and 9 were purified by a Sephadex LH-20 column $(2 \times 40 \mathrm{~cm})$ eluted with $\mathrm{MeOH}$ system to give compounds $\mathbf{1 0}(7 \mathrm{mg})$ and $\mathbf{9}(9 \mathrm{mg})$, respectively. E3 was purified by preparative reverse-phase HPLC eluted with $18 \% \mathrm{MeCN} / \mathrm{H}_{2} \mathrm{O}(+0.2 \% \mathrm{FA})$ to give compounds $14\left(t_{R}=26.5 \mathrm{~min}\right)$ and $8\left(t_{R}=30.5 \mathrm{~min}\right)$, and then compounds 14 and 8 were purified by a Sephadex LH-20 column $(2 \times 40 \mathrm{~cm})$ eluted with $\mathrm{MeOH}$ system to give compounds $14(8 \mathrm{mg})$ and $8(6.5 \mathrm{mg})$, respectively. E4 was chromatographed on a Sephadex LH-20 column $(2 \times 150 \mathrm{~cm})$ eluted with $\mathrm{MeOH}$ system to give E4-1 and E4-2, E4-2 was purified by preparative reverse-phase HPLC eluted with $37 \% \mathrm{MeOH} / \mathrm{H}_{2} \mathrm{O}(+0.2 \% \mathrm{FA})$ to give compound $18\left(7 \mathrm{mg}, \mathrm{t}_{\mathrm{R}}=29 \mathrm{~min}\right)$ and $\mathrm{E} 4-1$ was chromatographed on a Sephadex LH-20 column $(2 \times 150 \mathrm{~cm})$ eluted with $\mathrm{MeOH}$ system to give compound $22(10 \mathrm{mg})$.

B7 was purified with a Sephadex LH-20 column $(2 \times 150 \mathrm{~cm})$ eluted with $\mathrm{MeOH}$ system, and then four fractions (B7-1, B7-2, B7-3 and B7-4) were got. B7-2 was prepared on reverse-phase HPLC eluted with $41 \%$ $\mathrm{MeOH} / \mathrm{H}_{2} \mathrm{O}(+0.2 \% \mathrm{FA})$ to give compound 19 (7 mg, $\left.t_{R}=21 \mathrm{~min}\right), B 7-3$ was prepared on reverse-phase HPLC eluted with $35 \% \mathrm{MeOH} / \mathrm{H}_{2} \mathrm{O}(+0.2 \% \mathrm{FA})$ to give compound $20\left(7 \mathrm{mg}, \mathrm{t}_{\mathrm{R}}=20 \mathrm{~min}\right)$.

B8 was chromatographed on a Sephadex LH-20 column $(2 \times 150 \mathrm{~cm})$ eluted with $\mathrm{MeOH}$ system and then was purified by preparative reverse-phase HPLC eluted with $50 \% \mathrm{MeOH} / \mathrm{H}_{2} \mathrm{O}(+0.2 \% \mathrm{FA})$ to give compound $\mathbf{1 7}$ $\left(6 \mathrm{mg}, \mathrm{t}_{\mathrm{R}}=31 \mathrm{~min}\right)$.

B9 was chromatographed on a Sephadex LH-20 column $(2 \times 150 \mathrm{~cm})$ eluted with $\mathrm{MeOH}$ system and then was purified by preparative reverse-phase HPLC eluted with $55 \% \mathrm{MeOH} / \mathrm{H}_{2} \mathrm{O}(+0.2 \%$ FA) to give compound 21 $\left(7 \mathrm{mg}, \mathrm{t}_{\mathrm{R}}=29 \mathrm{~min}\right)$.

\section{Compound 1:}

5, 7-dihydroxy-8-((2R)-2-methylbutan-1-onyl)-methyl phenylacetate.

Colorless noodle-like crystal, $\mathrm{C}_{14} \mathrm{H}_{18} \mathrm{O}_{5},[\alpha]_{D}^{15}-9.5^{\circ}$ (c $0.5, \mathrm{CHCl}_{3}$ ), HR-ESI MS (positive ion mode) m/z: $289.1051[\mathrm{M}+\mathrm{Na}]^{+}$(calcd. for $\mathrm{C}_{14} \mathrm{H}_{18} \mathrm{O}_{5} \mathrm{Na}, 289.1052$ ). ${ }^{1} \mathrm{H}\left(500 \mathrm{M}, \mathrm{CD}_{3} \mathrm{OD}\right)$ and ${ }^{13} \mathrm{C}\left(125 \mathrm{MHz}, \mathrm{CD}_{3} \mathrm{OD}\right) \mathrm{NMR}$ data, see Table 1 .

\section{Compound 2:}

5, 7-dihydroxy-8-((2R)-2-methylbutan-1-onyl)-phenylacetic acid 7-O- $\beta$-D-glucopyranoside.

White amorphous powder $(\mathrm{MeOH}), \mathrm{C}_{19} \mathrm{H}_{26} \mathrm{O}_{10}$, HRESI MS (positive ion mode) $\mathrm{m} / \mathrm{z}: 437.1390[\mathrm{M}+\mathrm{Na}]^{+}$ (calcd. for $\mathrm{C}_{19} \mathrm{H}_{26} \mathrm{O}_{10} \mathrm{Na}$, 437.1424). ${ }^{1} \mathrm{H}$ (500 M, DMSO$\left.d_{6}\right)$ and ${ }^{13} \mathrm{C}\left(125 \mathrm{MHz}, \mathrm{DMSO}-d_{6}\right)$ NMR data, see Table 1.

\section{Neuraminidase inhibition activity}

NA inhibitory activity was determined by the commercial NA inhibitory screening kit (P0309, Beyotime Institute of Biotechnology, Jiangsu, China). The compound 2'-(4-methylumbelliferyl)-a-D-acetylneuraminic acid (MUNANA) is the substrate of NA. And cleavage of this substrate by NA produces a fluorescent product, $322 \mathrm{~nm}$ was the excitation wavelength and $450 \mathrm{~nm}$ was the emission wavelength. The intensity of fluorescence can reflect the activity of NA sensitively. The $\mathrm{IC}_{50}$ was calculated by plotting percent inhibition versus the inhibitor concentration and determination of each point was performed in duplicate. The actual and detailed experimental which was prepared according to literature method [31].

The inhibition rates were calculated as follows: [A1-A(background)-[A2-A(background)]/[A1-A (background)] $\times 100$ ], where $\mathrm{A} 1$ is the absorbance of the control, and $\mathrm{A} 2$ is the absorbance of the sample. $\mathrm{IC}_{50}$ was determined by plotting the percentage of NA activity against inhibitor concentration using software that came 
with the microplate reader. The values are expressed as the mean \pm SD of triplicate experiments.

\section{Molecular docking}

The cocrystal complex of N1 NA in complex with corresponding ligand oseltamivir downloaded from the protein data bank. (PDB ID code 2HU4) [32]. Before docking, the pre-existing ligand was removed out and hydrogen atoms and charges were added. The docking studies were performed using the Surflex-Dock module of Sybyl 8.1, and the maximum number of poses per ligand was set to 10 . The active site of the protein was automatically explored and created based on the previous ligand oseltamivir by the Surflex-Dock Protomol Generation Programme, and other parameters were set as default.

\section{Conclusions}

The two new compounds $(\mathbf{1}, 2)$ and compounds 11, 12, 14, 15, 19 and 20 showed better inhibitory activity against NA in vitro. By comparing with the structures of compound $11,12,14,15,19$ and 20, they all have one caffeoyl, and this is a possible reason that these compounds have better inhibitory activity against NA than other polyphenolic compounds. With the help of molecular docking, we had a preliminary understanding of the mechanism of the two new compounds (1-2)' NA inhibitory activity. According to the Lipinski's rule of five, compound $\mathbf{1}$ may be a better lead compound for anti-influenza.

Fractions 6 and polyphenolic compounds isolated from fractions 6 showed higher NA inhibition than that of the initial plant exacts (Tables 2,3). The findings of this study indicate that polyphenolic compounds and fractions 6 derived from P. cablin are potential NA inhibitors. This work was one of the evidence that $P$. cablin has better inhibitory activity against influenza, which not only enriches the compound library of $P$. cablin, but also facilitates further development and promises its therapeutic potential for the rising challenge of influenza diseases.

\section{Additional files}

Additional file 1. Spectra of isolated compounds 1-22.

Additional file 2. The data of NA inhibition experiments.

\section{Authors' contributions}

FL performed the experiments; $F L$ and $Y Z$ designed the study and interpreted the results; FL and CD collected test data and drafted the manuscript. All authors read and approved the final manuscript.

\section{Acknowledgements}

The authors are thankful to the authorities of School of Pharmaceutical Sciences of Central South University, for providing laboratory facilities. Gratitude is expressed to Shaogang Liu, Modern Analysis and Testing Central of CSU for ${ }^{1} \mathrm{H} N M R,{ }^{13} \mathrm{C}$ NMR spectrums.

\section{Competing interests}

The authors declare that they have no competing interests.

Received: 30 March 2016 Accepted: 12 July 2016

Published online: 10 August 2016

\section{References}

1. Salomon R, Webster RG (2009) The influenza virus enigma. Cell 136:402-410

2. Russell CJ, Webster RG (2005) The genesis of a pandemic influenza virus. Cell 123:368-371

3. Newman DJ, Cragg GM (2012) Natural products as sources of new drugs over the 30 years from 1981 to 2010. J Nat Prod 75:311-335

4. China Pharmacopoeia Editorial Board (2015) Pharmacopoeia of the People's Republic of China, vol 1. China Medical Science and Technology Press, Beijing, p 66

5. Kim KH, Beemelmanns C, Clardy J, Cao S (2015) A new antibacterial octaketide and cytotoxic phenylethanoid glycosides from Pogostemon cablin (Blanco) Benth. Bioorg Med Chem Lett 14:2834-2836

6. Kiuchi F, Matsuo K, Ito M, Qui TK, Honda G (2004) New sesquiterpene hydroperoxides with trypanocidal activity from Pogostemon cablin. Chem Pharm Bull 52:1495-1496

7. Huang LJ, Mu SZ, Zhang JX, Deng B, Song ZQ, Hao XJ (2009) Chemical constituents from involatile moiety of Pogostemon cablin. Zhongguo Zhong Yao Za Zhi 34:410-413

8. Miyazawa M, Okuno Y, Nakamura S, Kosaka H (2000) Antimutagenic activity of flavonoids from Pogostemon cablin. J Agric Food Chem 48:642-647

9. Buchi G, Goldman IM, Mayo DW (1966) The structures of two alkaloids from patchouli oil. J Am Chem Soc 88:3109-3113

10. Wang DH, Yin ZQ, Zhang QW, Ye WC, Zhang XQ, Zhang J (2010) Nonvolatile chemical constituents from Pogostemon cablin. Zhongguo Zhong Yao Za Zhi 35:2704-2707

11. Chen BL, Wang YJ, Guo H, Zeng GY (2016) Design, synthesis, and biological evaluation of crenatoside analogues as novel influenza neuraminidase inhibitors. Eur J Med Chem 109:199-205

12. Brown HC, Srebnik M, Bakshi RK, Cole TE (1987) Chiral synthesis via organoboranes. 10. Preparation of alpha-chiral acyclic ketones of exceptionally high enantiomeric excess from optically pure borinic esters. J Am Chem Soc 109:5420-5426

13. Otsuka H, Tamaki A (2002) Platanionosides D-J: megastigmane glycosides from the leaves of Alangium platanifolium (Sieb. et Zucc.) Harms var. platanifolium Sieb. et Zucc. Chem Pharm Bull (Tokyo) 50:390-394

14. Yamano Y, Ito M (2005) Synthesis of optically active vomifoliol and roseoside stereoisomers. Chem Pharm Bull (Tokyo) 53:541-546

15. Sueyoshi E, Liu H, Matsunami K, Otsuka H, Shinzato T, Aramoto M et al (2006) Bridelionosides A-F: megastigmane glucosides from Bridelia glauca f. balansae. Phytochemistry 67:2483-2493

16. He WJ, Fu ZH, Zeng GZ, Zhang YM, Han HJ, Yan H et al (2012) Terpene and lignan glycosides from the twigs and leaves of an endangered conifer, Cathaya argyrophylla. Phytochemistry 83:63-69

17. Kim JK, Si CL, Bae YS (2008) Phenylpropanoid glycosides from the leaves of Paulownia coreana. Nat Prod Res 22:241-245

18. Yan XJ, Bai XY, Liu QB, Liu S, Gao PY, Li LZ et al (2014) Two new glycosides from the fruits of Forsythia suspense. J Asian Nat Prod Res 16:376-382

19. Sun H, Liu M, Lin Z, Jiang H, Niu Y, Wang H et al (2015) Comprehensive identification of 125 multifarious constituents in Shuang-huang-lian powder injection by HPLC-DAD-ESI-IT-TOF-MS. J Pharm Biomed Anal 115:86-106

20. Afifi MS, Lahloub MF, el-Khayaat SA, Anklin CG, Rüegger H, Sticher O (1993) Crenatoside: a novel phenylpropanoid glycoside from Orobanche crenata. Planta Med 59:359-362

21. Fu YH, Huang LG, Wang XC, Li XB, Wu SL et al (2015) Studies on chemical constituents of psychotria straminea. Zhongguo Zhong Yao Za Zhi 40:2138-2143

22. Xiang L, Chen HN, Xu CM, Zhang SS, Wang HY (2008) Study on flavanoids from Salvia plebeia. Chin Pharm J 43:813-815

23. Jia Z, Liu Z, Wang C (1992) Phenylpropanoid glycosides from Pedicularis genus plants (I). Gaodeng Xuexiao Hua xue Xue bao 13:481 
24. Lai $X Y$, Zhao YY, Liang $H$ (2006) Studies on chemica constituents in flower of Abelmschus manihot. Zhongguo Zhong Yao Za Zhi 31:1597-1600

25. Zheng CJ, Huang BK, Han T, Zhang QY, Zhang H, Rahman K et al (2009) Nitric oxide scavenging lignans from vitex negundo seeds. J Nat Prod 72:1627-1630

26. Molinspiration (2016) Free web tools for cheminformatics community. http://www.molinspiration.com/. Accessed 9 July 2016

27. Lipinski CA, Lombardo F, Dominy BW, Feeney PJ (1997) Experimental and computational approaches to estimate solubility and permeability in drug discovery and development settings. Adv Drug Deliv Rev 23:3-25

28. Steindl T, Lange $T$ (2004) Influenza virus neuraminidase inhibitors: generation and comparison of structure-based and common feature pharmacophore hypotheses and their application in virtual screening. J Chem Inf Comput Sci 44:1849
29. Bossart-Whitaker P, Carson M, Babu Y, Smith C, Laver W, Air G (1993) Three-dimensional structure of influenza A N9 neuraminidase and its complex with the inhibitor 2-deoxy 2,3-dehydro-N-acetyl neuraminic acid. J Mol Biol 232:1069

30. Liu Y, Zhang J, Xu W (2007) Recent progress in rational drug design of neuraminidase inhibitors. Curr Med Chem 14:2872-2891

31. Wu J, Chen G, Xu X, Huo X, Wu S, Wu Z et al (2014) Seven new cassane furanoditerpenes from the seeds of Caesalpinia minax. Fitoterapia 92:168-176

32. Russell RJ, Haire LF, Stevens DJ, Collin PJ, Lin YP, Blackburn GM et al (2006) The structure of $\mathrm{H} 5 \mathrm{~N} 1$ avian influenza neuraminidase suggests new opportunities for drug design. Nature 443:45-49

\section{Submit your manuscript to a SpringerOpen ${ }^{\circ}$ journal and benefit from:}

- Convenient online submission

- Rigorous peer review

Immediate publication on acceptance

- Open access: articles freely available online

- High visibility within the field

- Retaining the copyright to your article 